\title{
Seventh survey of staffing in cardiology in the United Kingdom 1991
}

From the British Cardiac Society, the Cardiology Committee of the Royal College of Physicians, and the Trafford Centre for Medical Research, University of Sussex

\begin{abstract}
The Seventh Survey of Staffing in Cardiology was conducted with an index date of 31 July 1991. At that time the total number of posts for cardiologists in England and Wales, defined as individuals trained in the specialty and spending at least $40 \%$ of their professional time working in it, was 340 . Ten individuals worked part time only, making 335 whole time equivalent posts. This number increased from 1990 by $15(4 \cdot 7 \%)$. There were 67 cardiologists in Scotland and Northern Ireland, making a total for the United Kingdom of 407 posts (402 whole time equivalents). Sixteen Districts in England and Wales had no cardiologist at the time of the survey, and 31 other Districts had less than seven visiting sessions each week. The situation had not improved since the 1990 survey. The population of these 47 Districts is nearly nine million. Scotland had almost 800000 additional people served by Health Boards without resident cardiologists.
\end{abstract}

The number of senior registrars and lecturers is inadequate to provide a full period of training for most who advance to consultant status, and the situation will worsen from 1995 onwards. A major problem has been a top slice of 10 posts for a research allocation, few of which are occupied by individuals seeking a career in the specialty. These posts should be redesignated to increase training opportunities to counter the present shortfall and facilitate an expansion in consultant posts of at least $5 \%$ per annum over the next decade.

\section{(Br Heart J 1992;68:621-9)}

The first staffing survey for consultant and senior registrar posts in cardiology related to 1979 and 1980 and was published in $1981 .^{1}$ Thereafter the staffing surveys were biennial ${ }^{2-5}$ until 1990 when a decision was made to monitor changes each year. The present survey, with an index date of July 1991, is therefore the first of a new series that will be annual. The increase in the frequency of surveys was deemed necessary because of the rapid changes occurring within the National Health Service and because of our concerns that senior registrar numbers were not being adjusted sufficiently rapidly to avoid a dearth of fully trained individuals to fill consultant vacancies.

The surveys have become more complexand in general more accurate-over the past decade. In this survey, therefore, we have more detailed information than was available previously. A few previous errors have come to light (mostly relating to the 1986 survey that was completed by the Trafford Centre, but started elsewhere). We have also made some minor amendments to definitions to reflect changes in medical practice. For these reasons the 1991 data may not be strictly comparable to those published in previous surveys. But the comparisons we have made in this paper have been adjusted for these minor discrepancies except when otherwise specified.

\section{Methodology}

Although the index date for the current survey was July 1991, the survey did not begin until October of that year. The first stage was to identify individuals who should be counted as cardiologists or physicians with a major interest in the specialty. Previously we have relied on information from one contact in each Regional Health Authority, but this method may become less accurate with the increasing autonomy of district hospitals whether they have Trust status or function as directly managed units. We therefore approached instead one contact in each Health District of England and Wales and one contact in each Area Board of Scotland and Northern Ireland. We listed for them the names that we had already on file for individuals within their own Districts or Boards, with the request that they should draw our attention to any who had retired or died, and add names of any who could conceivably fall within our definitions. In January 1992 we sent 443 detailed questionnaires to all consultants who had been identified in the first stage of the survey. The net was deliberately cast wide and included some district physicians who had not previously been included on our database. In general we had excellent cooperation, and within six weeks $82 \%$ of the forms had been returned. Unfortunately we had considerable difficulty with many of the remainder. 
Reminder letters and duplicate forms were sent on three occasions, and all data were available only in early August. As the replies came back the information was compared with that already available on file, and some inconsistencies had to be resolved. Some questions were not completed on the first questionnaire and some responses were inappropriate-no doubt reflecting deficiencies in the forms. For example, some physicians in smaller district hospitals claimed incorrectly to practise interventional cardiology because we had not defined the meaning of that term.

After all the information had been completed, processed, and checked for omissions and errors it went through one final stage of verification. Tables giving all relevant data (except for planned retirement dates, which we regard as confidential) were sent to Regional contacts for scrutiny, and where necessary further minor changes were made. This three stage process is time consuming, but for the first time most information had been provided by individuals rather than by selected nominees in Regions and Districts. The detailed checking and cross checking has ensured that the data are as accurate as we can make them.

We continue to have difficulty in one important area, but the problem is inevitable. This relates to the type of work undertaken by cardiologists. The individuals in our survey are divided into four categories: first into those who practise either adult cardiology on the one hand or practise paediatric cardiology on the other, and secondly those who are regarded as spending all their professional time in the specialty (designated "cardiology only") and those who also have a commitment to general internal medicine (designated as having a "major interest" in the specialty). We have no difficulty in establishing whether practice is adult or paediatric, but the sessional commitment to the specialty is harder to define and inconsistencies have occurred from year to year-often because the information that we have been given has varied. Alteration of one of our definitions has compounded the problem. Many fully trained cardiologists working in cardiac centres and practising invasive and interventional cardiology do retain some commitment to general medical "take", and indeed this may well become more common as emphasis on specialised medicine increases and fewer physicians are regarded as generalists. We had been inconsistent in previous surveys, in that a commit- ment to "take" for emergency admissions sometimes influenced the category but sometimes did not. We now define a whole time commitment to the specialty (that is, "cardiology only") as "spending $80 \%$ or more of professional time in cardiology" so that having a general medical "take" is no longer-by itself-a decisive factor in deciding the appropriate category for a cardiovascular physician. This new definition has meant that a few individuals previously listed as having a "major interest" are now designated as practising "cardiology only". The total numbers, of course, are not affected. The definition of a physician with a "major interest" in cardiology requires that an individual must have had appropriate training in the specialty and must spend at least $40 \%$ of his or her professional time working exclusively within it. The major difficulty here relates to the training, which is clear cut for those appointed in recent years but more difficult for those who were senior registrars when training programmes were less clearly defined. This difficulty becomes less important as the years pass, but still gives rise to the occasional inconsistency.

Most consultants spend less than the 11 notional half days in hospital practice. For the purposes of the survey, however, they are counted as one whole time equivalent if they have seven sessions or more. Those with six sessions or less are counted as holding a part time post which-for simplicity-counts as 0.5 of a whole time equivalent. We must stress, however, that academic sessions and service sessions are regarded equally (a point sometimes misunderstood by those who complete our questionnaires)

One of the important functions of our survey is to identify districts that do not have adequate cardiological cover. We still have many district general hospitals without any individual who can be defined as a cardiologist according to the criteria mentioned above-a position that we regard as wholly unsatisfactory. In some cases provision is made by a visiting cardiologist, often from the Regional centre. We regard seven sessions as the minimum that will qualify a District as having cardiological cover. In this survey-but not in previous ones-we have distinguished those Districts that have no cover provided by a cardiologist listed in our survey from those that have inadequate (that is, less than seven sessions) cover.

A major centre has been defined as a cardiac

Table 1 Cardiovascular physicians in England and Wales, 1980-1991

\begin{tabular}{|c|c|c|c|c|c|c|c|}
\hline \multirow[b]{2}{*}{ Year } & \multicolumn{2}{|c|}{ Cardiology only ${ }^{\star}$} & \multicolumn{3}{|c|}{ Major interest } & \multirow{2}{*}{\multicolumn{2}{|c|}{ Totals }} \\
\hline & Adult & Paediatric & Adult & & Paediatric & & \\
\hline $\begin{array}{l}1980 \\
1982 \\
1984 \\
1986 \\
1988 \\
1990 \\
1991\end{array}$ & $\begin{array}{l}103 \\
111 \quad(8) \\
111 \quad(0) \\
119 \quad(8) \\
130 \quad(11) \\
145 \cdot 0(15 \cdot 0) \\
166 \cdot 5^{\star}(21 \cdot 5)\end{array}$ & $\begin{array}{ll}19 & \\
18 & (-1) \\
29 & (11) \\
31 & (2) \\
33 & (2) \\
39 \cdot 0 & (6 \cdot 0) \\
42 \cdot 0 & (3 \cdot 0)\end{array}$ & $\begin{array}{l}98 \\
117 \\
121 \\
118 \\
128 \\
134 \cdot 0 \\
124 \cdot 5^{\star}\end{array}$ & $\begin{array}{l}(19) \\
(4) \\
(-3) \\
(10) \\
(6.0) \\
(-9 \cdot 5)\end{array}$ & $\begin{array}{ll}3 & \\
4 & (1) \\
6 & (2) \\
2 & (-4) \\
0 & (-2) \\
2 \cdot 0 & (2 \cdot 0) \\
2 \cdot 0 & (0 \cdot 0)\end{array}$ & $\begin{array}{l}223 \\
250 \\
267 \\
270 \\
291 \\
320 \cdot 0 \\
335 \cdot 0\end{array}$ & $\begin{array}{l}(12 \cdot 11 \%) \\
(6 \cdot 80 \%) \\
(1 \cdot 12 \%) \\
(7 \cdot 78 \%) \\
(9.97 \%) \\
(4 \cdot 69 \%)\end{array}$ \\
\hline
\end{tabular}

The numbers in parentheses show change in numbers over the previous survey. The final column shows total percentage changes over the previous survey. Starting from 1990, figures are shown in whole time equivalents. 
Figure 1 Cardiovascular physicians England and Wales, 1980-1991.

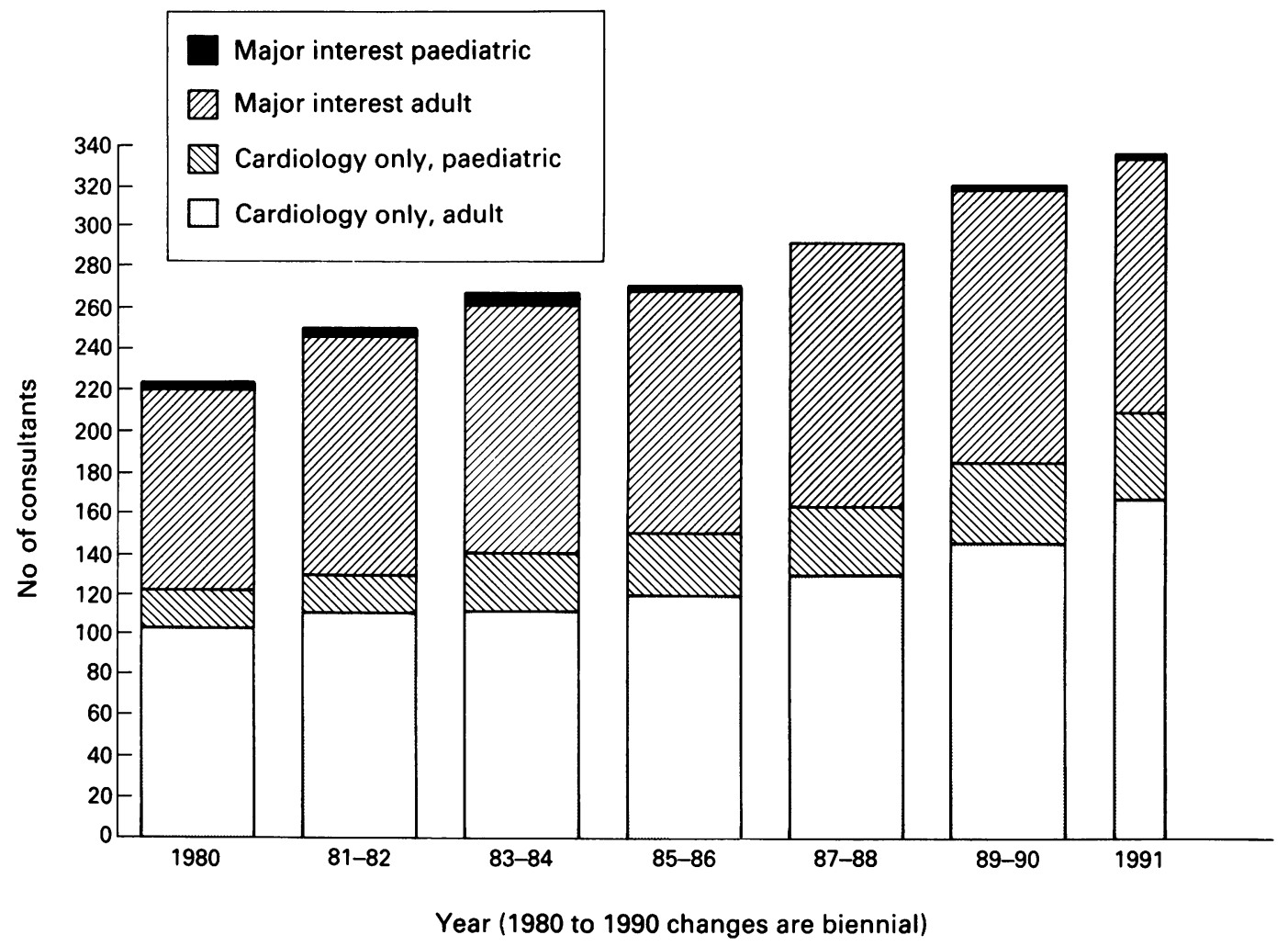

unit that has full investigatory facilities plus cardiac surgery.

\section{The data}

Relevant information from the 1991 survey is presented, as usual, in tables and graphs with a similar format to that used previously. Some general points should be noted. Blanks represent either zero values or data that are considered inappropriate. They do not imply missing values. Population figures have been obtained from the Office of Population Censuses and Surveys. They are estimates for mid 1990 (not 1991) and are given in thousands (with the figure after the decimal point representing hundreds rounded up or down). The hospitals that fall within the orbit of the
Special Health Authority are considered separately, though they fall within the boundaries of North East and North West Thames Regional Health Authorities. It should be noted that Wales has nine Health Districts but 18 district general hospitals, whereas in England the usual pattern is for one district general hospital within one Health District. The arrangements for Scotland and Northern Ireland are different. There are no District Health Authorities, but instead Area Boards which may have responsibility for more than one district general hospital. Where appropriate, 1990 data are given in parentheses. The following abbreviations are used in the tables: HD, Health District; HB, Health Board; HSSB, Health and Social Services Board; MC, major centre; WTE, whole time equivalent; $\mathrm{SR}$, senior registrar.

Table 2 Cardiovascular physicians by Region of England and Wales (31 July 1991)

\begin{tabular}{|c|c|c|c|c|c|c|c|c|c|c|c|}
\hline \multirow[b]{2}{*}{ Region } & \multirow{2}{*}{$\begin{array}{l}\text { Population } \\
\text { mid } \\
1990\end{array}$} & \multirow[b]{2}{*}{ HDs } & \multirow[b]{2}{*}{ MCs } & \multicolumn{3}{|c|}{ Cardiology only (WTEs) } & \multicolumn{3}{|c|}{ Major interest (WTEs) } & \multirow{2}{*}{$\begin{array}{l}\text { Total } \\
\text { WTEs }\end{array}$} & \multirow{2}{*}{$\begin{array}{l}\text { Total } \\
\text { individuals }\end{array}$} \\
\hline & & & & Adult & & Paediatric & Adult & & Paediatric & & \\
\hline $\begin{array}{l}\text { East Anglia } \\
\text { Mersey } \\
\text { NE Thames } \\
\text { NW Thames } \\
\text { North Western } \\
\text { Northern } \\
\text { Oxford } \\
\text { SE Thames } \\
\text { SW Thames } \\
\text { South Western } \\
\text { Trent } \\
\text { Wessex } \\
\text { West Midlands } \\
\text { Yorkshire } \\
\text { Wales } \\
\text { Special hospitals }\end{array}$ & $\begin{array}{l}2059 \cdot 0 \\
2402 \cdot 8 \\
3802 \cdot 9 \\
3498 \cdot 6 \\
4016 \cdot 1 \\
3075 \cdot 4 \\
2563 \cdot 9 \\
3658 \cdot 2 \\
2978 \cdot 6 \\
3262 \cdot 1 \\
4704 \cdot 5 \\
2940 \cdot 3 \\
5219 \cdot 3 \\
3655 \cdot 7 \\
2881 \cdot 4\end{array}$ & $\begin{array}{r}8 \\
10 \\
16 \\
13 \\
19 \\
16 \\
8 \\
15 \\
13 \\
11 \\
12 \\
10 \\
22 \\
17 \\
9 \\
4\end{array}$ & $\begin{array}{l}1 \\
2 \\
3 \\
2 \\
3 \\
1 \\
1 \\
4 \\
1 \\
1 \\
2 \\
1 \\
3 \\
3 \\
1 \\
4\end{array}$ & $\begin{array}{r}6.5 \\
6.0 \\
16.0 \\
15.0 \\
10.0 \\
8.5 \\
4.0 \\
16.0 \\
12.0 \\
9.5 \\
10.0 \\
3.0 \\
14.5 \\
12.5 \\
5.0 \\
18.0\end{array}$ & $\begin{array}{l}(4 \cdot 0) \\
(4 \cdot 0) \\
(15 \cdot 5) \\
(11 \cdot 0) \\
(9 \cdot 0) \\
(8 \cdot 5) \\
(4 \cdot 0) \\
(15 \cdot 0) \\
(9 \cdot 0) \\
(6 \cdot 0) \\
(8 \cdot 0) \\
(3 \cdot 0) \\
(14 \cdot 0) \\
(12 \cdot 0) \\
(4 \cdot 0) \\
(18 \cdot 0)\end{array}$ & $\begin{array}{c}3.0(3.0) \\
\\
2.0(1.0) \\
3.0(3.0) \\
3.0(3.0) \\
2.0(2.0) \\
4.0(4.0) \\
3.0(3.0) \\
2.0(1.0) \\
3.0(3.0) \\
3.0(3.0) \\
3.0(3.0) \\
1.0 \\
10.0(10.0)\end{array}$ & $\begin{array}{r}3.0 \\
6.0 \\
9.0 \\
6.0 \\
11.0 \\
9.0 \\
8.0 \\
9.0 \\
4.0 \\
4.0 \\
11.5 \\
10.0 \\
15.0 \\
10.0 \\
9.0\end{array}$ & $\begin{array}{l}(5 \cdot 5) \\
(6.0) \\
(9 \cdot 0) \\
(7 \cdot 0) \\
(12.0) \\
(9 \cdot 0) \\
(7 \cdot 0) \\
(9.0) \\
(6.0) \\
(5 \cdot 0) \\
(12.5) \\
(11.0) \\
(15.0) \\
(11.0) \\
(9.0)\end{array}$ & $\begin{array}{l}0(1) \\
1(1)\end{array}$ & $\begin{array}{r}9.5(9.5) \\
15.0(13.0) \\
25.0(24.5) \\
24.0(19.0) \\
24.0(24.0) \\
20.5(20.5) \\
14.0(13.0) \\
29.0(28.0) \\
16.0(16.0) \\
16.5(14.0) \\
24.5(22.5) \\
16.0(17.0) \\
32.5(32.0) \\
25.5(26.0) \\
15.0(13.0) \\
28.0(28.0)\end{array}$ & $\begin{array}{l}10(10) \\
15(13) \\
24(25) \\
24(19) \\
24(24) \\
21(21) \\
14(13) \\
30(29) \\
16(16) \\
17(14) \\
25(23) \\
16(17) \\
33(32) \\
26(26) \\
15(13) \\
30(28)\end{array}$ \\
\hline Totals & $50718 \cdot 8$ & 203 & 33 & $166 \cdot 5^{\star}$ & $(145 \cdot 0)$ & $42.0(39.0)$ & $124 \cdot 5^{\star}$ & $(134 \cdot 0)$ & $2(2)$ & $335.0(320.0)$ & $340(323)$ \\
\hline
\end{tabular}

Additional number of staff-grade cardiologists: one "cardiology only", one "major interest".

* "Cardiology only" physicians have been re-defined in 1991 as "spending more than $80 \%$ of their time in cardiology". By our previous definition there were 7.5 more "cardiology only" adult and 4.5 more "major interest" adult posts than in 1990.

The figures above include six vacancies (two in paediatric cardiology). 
Table 3 Cardiovascular physicians by Health Board in Scotland (31 July 1991)

\begin{tabular}{|c|c|c|c|c|c|c|c|}
\hline \multirow[b]{2}{*}{ Health Board } & \multirow{2}{*}{$\begin{array}{l}\text { Population } \\
\text { mid } \\
1990\end{array}$} & \multirow[b]{2}{*}{$M C s$} & \multicolumn{2}{|c|}{ Cardiology only } & \multicolumn{2}{|c|}{ Major interest } & \multirow[b]{2}{*}{ Totals } \\
\hline & & & Adult & Paediatric & Adult & Paediatric & \\
\hline Argyll and Clyde & $440 \cdot 4$ & & & & $2(2)$ & & $2(2)$ \\
\hline Ayrshire and Arran & 375.4 & & & & $2(2)$ & & $2(2)$ \\
\hline Borders & $103 \cdot 5$ & & & & & & \\
\hline Dumfries and Galloway & $148 \cdot 4$ & & & & $1(1)$ & & $1(1)$ \\
\hline Fife & 345.9 & & & & & & \\
\hline Forth Valley & $272 \cdot 1$ & & & & & & \\
\hline Grampian & $506 \cdot 1$ & 1 & $3(3)$ & & & & $3(3)$ \\
\hline Greater Glasgow & $927 \cdot 7$ & 2 & $8(9)$ & $2(3)$ & $7(6)$ & $1(0)$ & $18(18)$ \\
\hline Highland & $204 \cdot 3$ & & & & $1(1)$ & & 1 (1) \\
\hline Lanarkshire & 562.5 & & & & $3(3)$ & & $3(3)$ \\
\hline Lothian & $749 \cdot 6$ & 1 & $7(7)$ & $2(2)$ & $1(1)$ & & $10(10)$ \\
\hline Orkney & 19.6 & & & & & & \\
\hline Shetlands & $22 \cdot 3$ & & & & & & \\
\hline Tayside & $394 \cdot 0$ & & $2(2)$ & & & & $2(2)$ \\
\hline Western Isles & $30 \cdot 7$ & & & & & & \\
\hline Totals & $5102 \cdot 4$ & 4 & $20(21)$ & $4(5)$ & $17(16)$ & $1(0)$ & $42(42)$ \\
\hline
\end{tabular}

Table 4 Cardiovascular physicians by Health Board in Northern Ireland ( 31 July 1991)

\begin{tabular}{|c|c|c|c|c|c|c|c|}
\hline \multirow[b]{2}{*}{ Health Board } & \multirow{2}{*}{$\begin{array}{l}\text { Population } \\
\text { mid } \\
1990\end{array}$} & \multirow[b]{2}{*}{$M C s$} & \multicolumn{2}{|c|}{ Cardiology only } & \multicolumn{2}{|c|}{ Major interest } & \multirow[b]{2}{*}{ Totals } \\
\hline & & & Adult & - Paediatric & Adult & Paediatric & \\
\hline $\begin{array}{l}\text { Eastern HSSB } \\
\text { Northern HSSB } \\
\text { Southern HSSB } \\
\text { Western HSSB }\end{array}$ & $\begin{array}{l}647 \cdot 6 \\
386 \cdot 4 \\
292 \cdot 1 \\
262 \cdot 5\end{array}$ & 1 & $\begin{array}{l}11(11) \\
1(0) \\
2(0)\end{array}$ & $2(2)$ & $\begin{array}{ll}1 & (2) \\
3 & (4) \\
3 & (3) \\
2 & (3)\end{array}$ & & $\begin{aligned} 14 & (15) \\
4 & (4) \\
3 & (3) \\
4 & (3)\end{aligned}$ \\
\hline Totals & $1589 \cdot 4$ & 1 & $14(11)$ & $2(2)$ & $9(12)$ & $0(0)$ & $25(25)$ \\
\hline
\end{tabular}

\section{Comments}

STAFFING: CONSULTANT GRADE

Table 1 shows that the number of cardiologists in England and Wales has increased progressively from 1980 to 1991 with only a very small apparent increase in 1986. This small increase was spurious. The 1986 survey was originally undertaken from the offices of the British Cardiac Society but was not completed at the time. The data-as they were available-were eventually published with the 1988 survey. Some of the errors from 1986 have been corrected only recently. The total increase from 1980 to 1991 is, however, substantially accurate. It shows an overall increase of 112 $(50 \%)$, but the biennial growth has averaged only $7.6 \%(3.8 \%$ annual growth). Even the

Table 5 Number of retirements expected each year for cardiovascular physicians in England and Wales (as of 31 July 1991)

\begin{tabular}{|c|c|c|c|c|c|}
\hline \multirow[b]{2}{*}{ Year } & \multicolumn{2}{|c|}{ Cardiology only } & \multicolumn{2}{|c|}{ Major interest } & \multirow[b]{2}{*}{ Total } \\
\hline & Adult & Paediatric & Adult & Paediatric & \\
\hline Vacancies & 3 & 2 & 1 & & 6 \\
\hline 1991 & 3 & & 1 & & $4(4)$ \\
\hline 1992 & 4 & & 3 & & $7(2)$ \\
\hline 1993 & 2 & 1 & & & $3(5)$ \\
\hline 1994 & 3 & & 2 & & $5(4)$ \\
\hline 1995 & 6 & & 3 & 1 & $10(6)$ \\
\hline 1996 & 2 & 1 & 6 & & $9(5)$ \\
\hline 1997 & 3 & & 3 & & $6(13)$ \\
\hline 1998 & 1 & 1 & 2 & & $4(5)$ \\
\hline 1999 & 4 & 1 & 6 & & 11 (11) \\
\hline 2000 & 9 & 1 & 9 & & 19 (14) \\
\hline 2001 & 4 & 1 & 3 & & $8(7)$ \\
\hline 2002 & 2 & & 6 & & $8(12)$ \\
\hline 2003 & 2 & 1 & 9 & & $12(6)$ \\
\hline 2004 & 10 & 4 & 4 & & $18(12)$ \\
\hline 2005 & 6 & 3 & 4 & & 13 (11) \\
\hline 2006 & 3 & 1 & 2 & 1 & 7 \\
\hline 2007 & 6 & $i$ & 6 & & 13 \\
\hline 2008 & 6 & 1 & 9 & & 16 \\
\hline 2009 & 7 & 1 & 3 & & 11 \\
\hline 2010 & 12 & 2 & 8 & & 22 \\
\hline After 2010 & 73 & 20 & 35 & & 128 \\
\hline Totals & 171 & 42 & 125 & 2 & 340 \\
\hline
\end{tabular}

increase from 1990 to 1991 of $4.7 \%$ is marginally below the $5 \%$ "target" that we regard as reasonable. Most of the increase is seen in the column for adult "cardiology only" with an apparent decrease in numbers for adult "major interest". There was no real decline in the "major interest" posts: the change is due to the alteration in designation mentioned above. The alteration in designation does not, of course, affect the overall numbers but does reflect more accurately the varying commitments of cardiologists. After allowing for this change in designation there were $7 \cdot 5$ more "cardiology only" posts and 4.5 more "major interest" adult posts than in 1990 . In the column for paediatric posts with a "major interest" the negative numbers reflect either changes in posts that became "cardiology only" or other changes in designation-there were no true losses. Figure 1 shows the increase in numbers of cardiologists that has occurred over an 11 year period. The last column is narrower because it shows data for only one year rather than two. There is slight distortion in the comparison between "cardiology only" and "major interest" in adult posts for the reason mentioned above.

Table 2 shows the total of cardiologists in each Region. In this survey we present an additional column so we show both total individuals and whole time equivalents. Ten cardiologists are working part time (that is, less than seven sessions of hospital practice). Two cardiologists share their time between two Regions, and in this table are therefore shown as a half post in each. Most Regions show an increase in numbers, though five are unchanged and two show a small decrease. The loss of one individual in Wessex represents a cardiovascular epidemiologist who moved to London 
Figure 2 Retirements expected 1991-2010

England and Wales.

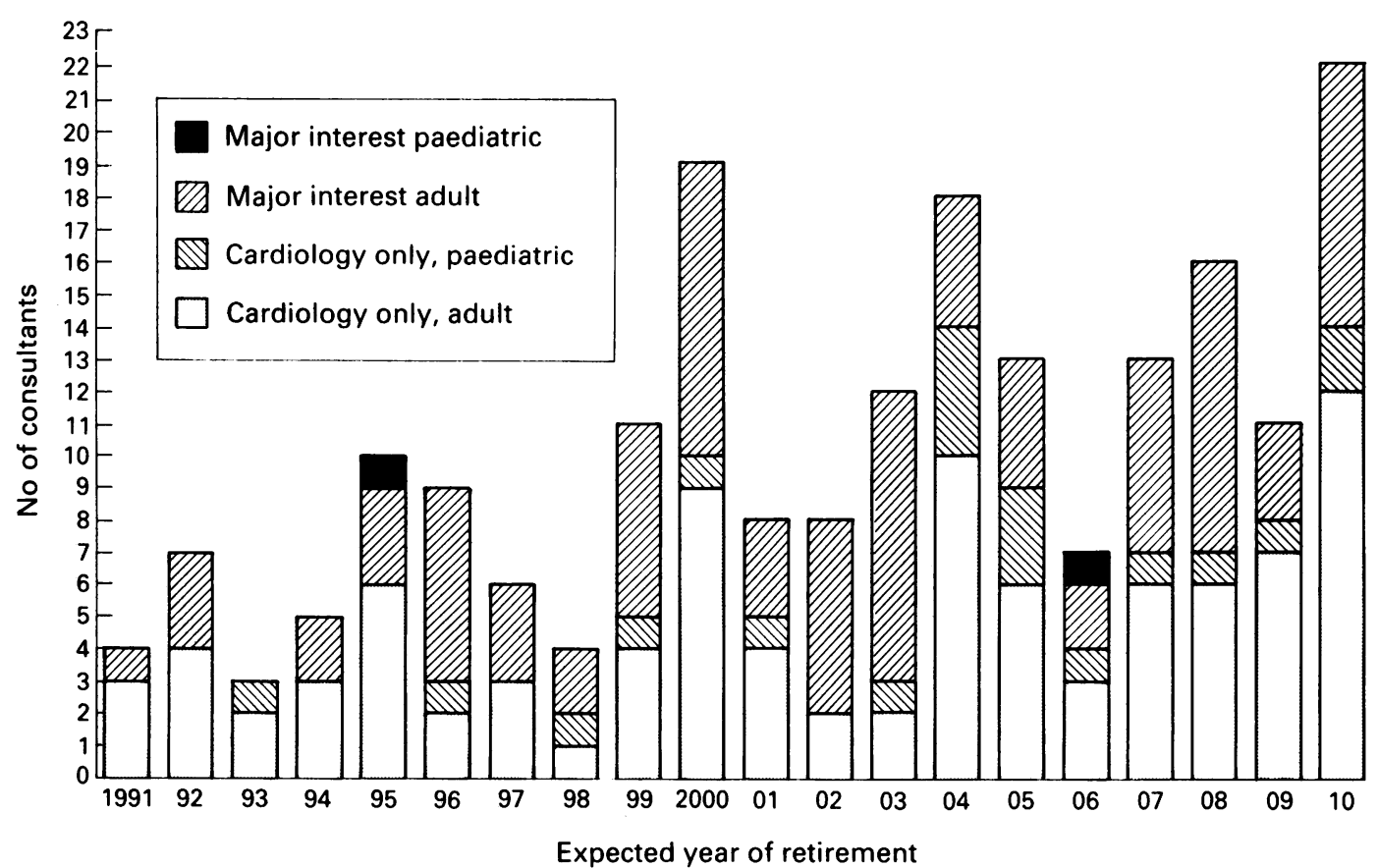

and was not replaced locally. The small change in Yorkshire was because of an alteration in sessional commitment for one individual. There has been no true loss within any Region. Marked discrepancies persist between the different Regions in the number of cardiologists per million population, ranging from 4.6 in East Anglia to 7.9 in South East Thames. The average for England and Wales was 6.6.

Tables 3 and 4 show comparable data for Scotland and Northern Ireland. There are no part time posts in these countries, so all figures represent individuals. In the Scottish data, two cardiologists have slightly reduced their commitment to the specialty so that they have changed from "cardiology only" to "major interest". One "major interest" post has become "cardiology only". The figures include one paediatric "cardiology only" post that was vacant on the date of the survey. There is no change overall in the number of consultants,

Table 6 Number of retirements expected each year for cardiovascular physicians in Scotland (as of 31 July 1991)

\begin{tabular}{|c|c|c|c|c|c|}
\hline \multirow[b]{2}{*}{ Year } & \multicolumn{2}{|c|}{ Cardiology only } & \multicolumn{2}{|c|}{ Major interest } & \multirow[b]{2}{*}{ Total } \\
\hline & Adult & Paediatric & Adult & Paediatric & \\
\hline $\begin{array}{l}\text { Vacancies } \\
1991\end{array}$ & & 1 & & & 1 (1) \\
\hline 1992 & & & 1 & & $1(1)$ \\
\hline 1993 & & & & & (1) \\
\hline 1994 & & & 1 & & 1 \\
\hline 1995 & & & 1 & & 1 (3) \\
\hline 1997 & 1 & & & & $1(1)$ \\
\hline 1998 & 1 & & 2 & & 3 \\
\hline 1999 & & & 1 & 1 & 2 \\
\hline 2000 & & & 1 & & $1(2)$ \\
\hline 2002 & 1 & & 1 & & 2 \\
\hline 2003 & 1 & 1 & & & $2(2)$ \\
\hline 2004 & & & & & (2) \\
\hline 2005 & 1 & & 1 & & 2 (3) \\
\hline 2006 & & 1 & 2 & & 3 \\
\hline 2007 & 1 & & 1 & & 2 \\
\hline 2008 & 3 & & 1 & & 4 \\
\hline 2009 & 1 & & & & 1 \\
\hline 2010 & 2 & & & & 2 \\
\hline After 2010 & 8 & 1 & 4 & & 13 \\
\hline Totals & 20 & 4 & 17 & 1 & 42 \\
\hline
\end{tabular}

Years omitted: no retirements expected. population at $8 \cdot 2$ is higher than in England and Wales. For Northern Ireland, the total number of cardiologists is unchanged overall at 25 , with a ratio per million population of $15 \cdot 7$. There was one true gain in an adult "cardiology only" post. One of the apparent losses in the "major interest" post reflected an error in the previous survey. Other changes are due to alterations in designation.

Table 5 and figure 2 show the number of retirements predicted from the date of the survey (31 July 1991) to the year 2010. The numbers in parentheses in table 5 show the corresponding predictions given with the 1990 data. One important change has occurred. The 1990 data showed an almost stepwise increase in the number of retirement vacancies predicted from 1997 onwards-a change that caused us considerable concern because of the predicted inadequacy in the number of trained senior registrars to fill these posts. Figure 2 shows a smoother increase than the corresponding figure in our previous publication. The change reflects the decision by many consultants to consider retirement earlier than they had previously planned. We have calculated the intended retirement age at the time of our last four surveys. On average, consultants in 1986 stated that they would retire at 64.22 years, in 1988 at $64 \cdot 16$ years, and in 1990 at 64 years. But by 1991 there had been a sharp decrease to 63 years. The number of retirements that occurred over the previous decade was fairly steady, averaging around six per annum with additional posts becoming vacant because of deaths and new appointments. The table shows that the pattern still changes fairly abruptlynot now from 1997 as previously predicted, but (because of earlier retirements) from 1995 onwards. Tables 6 and 7 show comparable data for Scotland and Northern Ireland. In these two countries there are far fewer posts. Though the tables show no clear evidence of any trend but the ratio of cardiologists per million 
Table 7 Number of retirements expected each year for cardiovascular physicians in Northern Ireland (as of 31 July 1991)

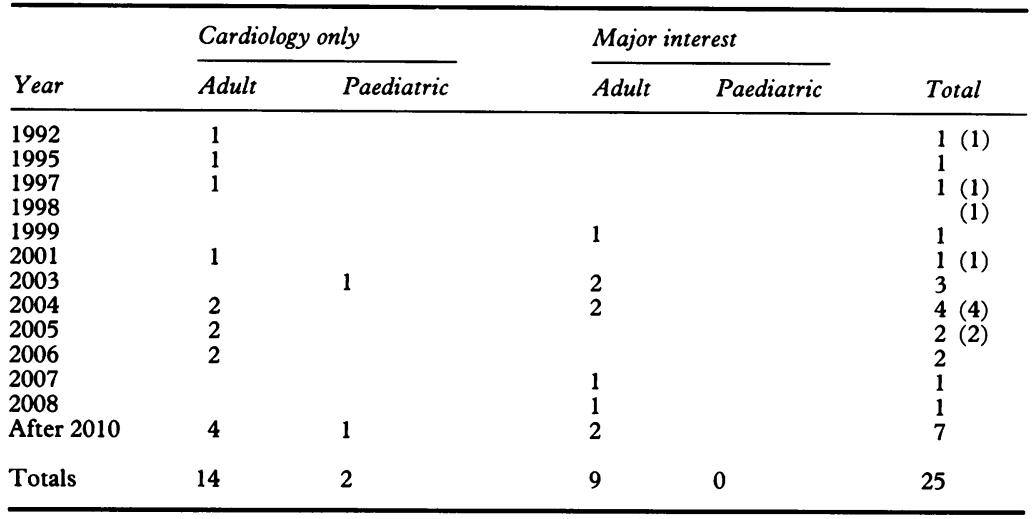

Years omitted: no retirements expected.

towards early retirement, the complete data do show a trend similar to that in England and Wales.

Table 8 shows Health Districts without cardiologists in England and Wales. Much interest always centres around the number of Health Districts with only minimal provision for cardiological services. We believe that every Health District should have at least one individual trained in the specialty and working at least $40 \%$ of professional time within it. This is important not only for the time that the cardiologist can spend in service work, but also for the benefit of the influence that will extend to other staff members and to the training for junior medical staff whatever their medical specialty. In this report we have distinguished between the Health Districts that have fewer than seven sessions (sometimes only two or three sessions provided by a visiting cardiologist) and those that have no physician who meets our modest criteria. The picture is gloomy: in the 12 months since the last survey none of the Health Districts acquired a cardiologist. Three Districts fall into this category for the first time-designated in the table as "losses". Two of these were real but only because of sessional changes. The other represented a previous error. There were, however, no losses in terms of individuals. The previous report stated that 31 Districts were "completely without" cardiology, but that did not take account of seven
Districts that have occasional visits, and a few others may not have declared them in previous surveys. Nearly nine million people live in Districts without adequate provision for cardiology. This figure has increased slightly since the last survey. The position of Wales is complex because the nine Health Districts have between them 18 district general hospitals. We do not have population figures for the individual hospitals, but a total of 10 of them are without adequate cardiology. (Thus the data for Wales are not strictly comparable with those for England, and the position is worse than the data by Health District imply).

Table 9 shows comparable data for Scotland. Few hospitals within these Boards have even minor provision from visiting cardiologists. We have no table for Northern Ireland, but three hospitals had no separate provision. In these hospitals, however, the arrangements for cover were unusually good.

\section{STAFFING: SENIOR REGISTRAR GRADE}

Table 10 compares the numbers of cardiovascular physicians in each Region of England and Wales with the number of senior registrars and equivalents in post. Overall, the ratio of consultants to senior registrars is 5.9:1. There are no wide discrepancies in the ratios: the figure is smallest for Oxford, which has only eight Health Districts, and highest for South Western Region. Three of the senior registrar posts and six of the consultant posts shown in this table were vacant on the survey date but they have been included because the vacancies were shortly to be filled.

Our allocation from the Joint Planning Advisory Committee (JPAC) is 60 posts for adult and paediatric cardiology, of which 10 are "top-sliced" for a research allocation and two are top-sliced for the part time training of four individuals. The system for research allocation is bizarre and precludes effective planning. Each specialty is required to contribute towards a central pool from which posts are then made available for allocation by the Association of Medical Research Charities (including the British Heart Foundation) and by Regional Health Authorities. The allocation, however, is

Table 8 Health Districts without cardiology by Region of England and Wales (31 July 1991)

\begin{tabular}{|c|c|c|c|c|c|c|}
\hline Region & $\begin{array}{l}\text { Population } \\
\text { mid } 1990\end{array}$ & $H D s$ & $\begin{array}{l}\text { HDs } \\
\text { with } \\
<7 \text { sessions }\end{array}$ & Losses & $\begin{array}{l}\text { HDs } \\
\text { completely } \\
\text { without }\end{array}$ & $\begin{array}{l}\text { Population with } \\
\text { less than } 7 \\
\text { sessions/HD }\end{array}$ \\
\hline $\begin{array}{l}\text { East Anglia } \\
\text { Mersey } \\
\text { NE Thames } \\
\text { NW Thames } \\
\text { North Western } \\
\text { Northern } \\
\text { Oxford } \\
\text { SE Thames } \\
\text { SW Thames } \\
\text { South Western } \\
\text { Trent } \\
\text { Wessex } \\
\text { West Midlands } \\
\text { Yorkshire } \\
\text { Wales } \\
\text { Special hospitals }\end{array}$ & $\begin{array}{l}2059 \cdot 0 \\
2402 \cdot 8 \\
3802 \cdot 9 \\
3498 \cdot 6 \\
4016 \cdot 1 \\
3075 \cdot 4 \\
2563 \cdot 9 \\
3658 \cdot 2 \\
2978 \cdot 6 \\
3262 \cdot 1 \\
4704 \cdot 5 \\
2940 \cdot 3 \\
5219 \cdot 3 \\
3655 \cdot 7 \\
2881 \cdot 4\end{array}$ & $\begin{array}{r}8 \\
10 \\
16 \\
13 \\
19 \\
16 \\
8 \\
15 \\
13 \\
11 \\
12 \\
10 \\
22 \\
17 \\
9 \\
4\end{array}$ & $\begin{array}{ll}2 & (2) \\
5 & (5) \\
3 & (2) \\
3 & (3) \\
5 & (5) \\
6 & (6) \\
1 \\
1 \\
3 & (3) \\
3 & (3) \\
3 & (2) \\
2 & (2) \\
6 & (6) \\
3 & (3) \\
2 & (2)\end{array}$ & 1 & $\begin{array}{l}3 \\
1 \\
4 \\
2\end{array}$ & $\begin{array}{r}421 \cdot 9 \\
973 \cdot 6 \\
726 \cdot 6 \\
723 \cdot 3 \\
869 \cdot 6 \\
998 \cdot 9 \\
\\
271 \cdot 7 \\
736 \cdot 8 \\
571 \cdot 6 \\
636 \cdot 6 \\
251 \cdot 4 \\
1036 \cdot 1 \\
490 \cdot 9 \\
231 \cdot 1\end{array}$ \\
\hline Totals & $50718 \cdot 8$ & 203 & $47(44)$ & 3 & 16 & $8940 \cdot 1(8305 \cdot 3)$ \\
\hline
\end{tabular}


Table 9 Scottish Health Boards without cardiologists (31 July 1991)

\begin{tabular}{lc}
\hline Health Board & Population without \\
\hline Borders & $103 \cdot 5$ \\
Fife & $345 \cdot 9$ \\
Forth Valley & $272 \cdot 1$ \\
Orkney & $19 \cdot 6$ \\
Shetlands & $22 \cdot 3$ \\
Western Isles & $30 \cdot 7$ \\
Total & $794 \cdot 1$ \\
\hline
\end{tabular}

not specialty specific. There is no guarantee that a specialty will receive back the same number of posts that have been contributed to the pool. Cardiology is called upon to make the largest contribution (10 posts) but the reason for this high number is historical and unclear. At the present time we have only four research posts allocated to us (included in the column labelled "supernumerary"), and we believe we had approximately the same number at the time of recent surveys. Thus in practice a quota of senior registrars is calculated and then subjected to a large and arbitrary "research" cut. We are required also to provide two posts for part time training, but as far as we know we have never used our complete allocation. We are close at the moment, with three individuals in post. Although we have never used our allocation, we were told at a recent JPAC review that it should be increased on the basis of our overall numbers, but fortunately our appeal against this decision was allowed. The system of "top-slicing" has kept our overall numbers below our allocation from 1984 to the present time. Our survey has uncovered an apparent anomaly: we have a total of 50 posts in the NHS and academic categories whereas our quota is 48 , but this small difference does not compensate for the overall deficit.

Table 11 shows comparable data for Scotland and Northern Ireland.

Theoretically, the number of senior registrars completing their training period in any year should balance the number of consultant retirements, with a small correction for growth in the specialty based on historical data. Fluctuations from year to year would be ex- pected unless the specialty were so large that variables cancelled out. In all of our surveys, however, we have seen appreciable deficits in consultant retirements in relation to the number of senior registrars expected to complete their training. For the five years 1992 to 1996 there should be 55 senior registrars available (including vacant posts) to fill only 34 posts, an excess of 21 senior registrars and lecturers (table 12). This figure does not cause us concern because we have seen a similar predicted excess in each survey, yet the relative dearth of trained senior registrars has remained unaffected or increased. The corresponding figure for 1990 was 17 and for 1988 it was 30 . In this survey we have for the first time sought and included trainees in non-approved posts who do (or may wish to) compete for consultant cardiology vacancies. The 14 individuals who have been identified include some in other specialties such as clinical pharmacology. Many would have other avenues open to them. The phenomenon is not new but it has not been well recognised. We note that seven of 22 recent appointments were taken by individuals who were not in JPAC approved cardiology training posts. Without this supplement to our trainee numbers we would by now have faced a crisis. Further evidence of a dearth of senior registrars is provided by an examination of the length of time that consultants appointed in the 12 months since the survey date spent as senior registrars. Six had completed their four years training. But seven had completed less than four years, an additional seven had completed less than three years, and two more had completed less than two years training at the time of appointment. It is also clear from the data shown in table 12 that in July 1991 most of the senior registrars were due to complete their training from 1994 onwards, in other words they had been only recently appointed to the grade.

Tables 13 and 14 show comparable data for Scotland and Northern Ireland. The numbers for both are small but they suggest that the combination of new consultant appointments, earlier retirements, or deaths could very easily create an important negative balance in either of these countries.

Table 10 Cardiovascular physicians and senior registrars by Region of England and Wales (31 July 1991)

\begin{tabular}{|c|c|c|c|c|c|c|c|c|c|c|c|}
\hline \multirow[b]{2}{*}{ Region } & \multirow[b]{2}{*}{$H D s$} & \multirow[b]{2}{*}{$M C s$} & \multicolumn{3}{|l|}{ Consultants } & \multicolumn{5}{|c|}{ Senior registrars } & \multirow[b]{2}{*}{$\begin{array}{l}\text { Ratio of } \\
\text { consultants:SRs }\end{array}$} \\
\hline & & & $\begin{array}{l}\text { Cardiology } \\
\text { only }\end{array}$ & $\begin{array}{l}\text { Major } \\
\text { interest }\end{array}$ & Total & NHS & Acad. & $\begin{array}{l}\text { Super- } \\
\text { numerary }\end{array}$ & $\begin{array}{l}\text { Total } \\
\text { WTEs }\end{array}$ & $\begin{array}{l}\text { Total SR } \\
\text { individuals }\end{array}$ & \\
\hline $\begin{array}{l}\text { East Anglia } \\
\text { Mersey } \\
\text { NE Thames } \\
\text { NW Thames } \\
\text { North Western } \\
\text { Northern } \\
\text { Oxford } \\
\text { SE Thames } \\
\text { SW Thames } \\
\text { South Western } \\
\text { Trent } \\
\text { Wessex } \\
\text { West Midlands } \\
\text { Yorkshire } \\
\text { Wales } \\
\text { Special hospitals }\end{array}$ & $\begin{array}{r}8 \\
10 \\
16 \\
13 \\
19 \\
16 \\
8 \\
15 \\
13 \\
11 \\
12 \\
10 \\
22 \\
17 \\
9 \\
4\end{array}$ & $\begin{array}{l}1 \\
2 \\
3 \\
2 \\
3 \\
1 \\
1 \\
4 \\
1 \\
1 \\
2 \\
1 \\
3 \\
3 \\
1 \\
4\end{array}$ & $\begin{array}{r}7 \\
9 \\
15 \\
17 \\
13 \\
12 \\
6 \\
21 \\
12 \\
13 \\
12 \\
6 \\
18 \\
16 \\
6 \\
30\end{array}$ & $\begin{array}{r}3 \\
6 \\
9 \\
7 \\
11 \\
9 \\
8 \\
9 \\
4 \\
4 \\
13 \\
10 \\
15 \\
10 \\
9\end{array}$ & $\begin{array}{l}10 \\
15 \\
24 \\
24 \\
24 \\
21 \\
14 \\
30 \\
16 \\
17 \\
25 \\
16 \\
33 \\
26 \\
15 \\
30\end{array}$ & $\begin{array}{l}1 \\
3 \\
3 \\
3 \\
3 \\
2 \\
1 \\
2 \\
2 \\
2 \\
2 \\
2 \\
2 \\
2 \\
1 \\
1\end{array}$ & $\begin{array}{l}1 \\
2 \\
1 \\
2 \\
2 \\
2 \\
1 \\
1\end{array}$ & $\begin{array}{l}1.0 \\
1.0 \\
0.5 \\
1.0\end{array}$ & $\begin{array}{l}2 \cdot 0 \\
3 \cdot 0 \\
3 \cdot 0 \\
4 \cdot 0 \\
3 \cdot 5 \\
3 \cdot 0 \\
3 \cdot 0 \\
4 \cdot 0 \\
2 \cdot 0 \\
2 \cdot 0 \\
4 \cdot 0 \\
2 \cdot 0 \\
4 \cdot 0 \\
4 \cdot 0 \\
4 \cdot 0 \\
8 \cdot 0\end{array}$ & $\begin{array}{l}2 \\
3 \\
3 \\
4 \\
4 \\
3 \\
3 \\
5 \\
2 \\
2 \\
4 \\
2 \\
4 \\
4 \\
4 \\
8\end{array}$ & $\begin{array}{l}5 \cdot 0 \\
5 \cdot 0 \\
8 \cdot 0 \\
6 \cdot 0 \\
6 \cdot 0 \\
7 \cdot 0 \\
4 \cdot 7 \\
6 \cdot 0 \\
8 \cdot 0 \\
8 \cdot 5 \\
6 \cdot 3 \\
8 \cdot 0 \\
8 \cdot 3 \\
6.5 \\
3 \cdot 8 \\
3 \cdot 8\end{array}$ \\
\hline Totals & 203 & 33 & $213(186)$ & $127(137)$ & $340(323)$ & 38 & 12 & $5 \cdot 5$ & $55 \cdot 5$ & 57 & $5 \cdot 9$ \\
\hline
\end{tabular}

$\star$ Individuals not WTEs.

Three of the SR posts shown were vacant on the survey date. 
Table 11 Cardiovascular physicians and senior registrars in Scotland and Northern Ireland (31 July 1991)

\begin{tabular}{lllllll}
\hline & No of HBs & No of MCs & $\begin{array}{l}\text { Cardiology } \\
\text { only }\end{array}$ & $\begin{array}{l}\text { Major } \\
\text { interest }\end{array}$ & $\begin{array}{l}\text { Total } \\
\text { cardiologists }\end{array}$ & $\begin{array}{l}\text { Senior } \\
\text { registrars }\end{array}$ \\
\hline Scotland & 15 & 4 & 24 & 18 & 42 & 7 \\
Northern Ireland & 4 & 1 & 16 & 9 & 25 & 4 \\
\hline
\end{tabular}

Figures for Northern Ireland include one SR vacancy.

\section{Staffing: a statement of need}

By any reasonable yardstick, the provision of cardiological services in the United Kingdom falls far short of a level that could be considered reasonable for an advanced country. While this is true of many specialties, cardiology has a unique claim: heart disease is by far the most important cause of premature mortality and is an important cause of morbidity at all ages. We have available the possibility of prevention, of medical treatment, of surgical treatment, and of rehabilitation. These facilities are not only poorly resourced but are often unavailable because of inadequate staffing levels. We appreciate that ideal levels of provision are unattainable and that a compromise is necessary. The target that was set out at the time of the Sixth Biennial Survey was modest. It called for 157 new consultant posts over a 10 year period. This is the minimum necessary for acceptable staffing levels in our cardiac centres and district general hospitals.

For the centres we need to provide sufficient cardiologists for the 500 coronary operations and the 250 angioplasties per million population per year recommended in the Fourth Joint Colleges Report ${ }^{6}$ - this total falling well short of what would be required to deal adequately with the burden of coronary disease, particularly in the elderly whose requirement for interventional cardiology in the United Kingdom receives too little consideration.

For a district general hospital we require at least one trained cardiologist, and for populations of over a quarter of a million we require two. We emphasise that a growth of $5 \%$ per annum, which we have still not attained, could meet these twin objectives by the year 2000 , but this makes no allowance for advances (such as arrhythmology which can be highly effective with a favourable cost-benefit ratio) nor does it go any way to correct the service load on senior registrars and registrars. Calls for shorter training programmes must recognise the special needs for practical experience in cardiology but no appropriate progress can be made while the contribution by trainees to service needs is so great and the time for structured teaching

Table 12 Contract expiry dates for senior registrars compared with retirement dates for consultants in England and Wales (31 July 1991)

\begin{tabular}{lcccc}
\hline Year & $\begin{array}{l}\text { Consultants } \\
\text { retiring }\end{array}$ & $\begin{array}{l}\text { Approved } \\
\text { SRs available }\end{array}$ & Balance & $\begin{array}{c}\text { (Other SRs } \\
\text { competing) }\end{array}$ \\
\hline 1992 & 7 & 4 & -3 & $(1)$ \\
1993 & 3 & 9 & 6 & $(4)$ \\
1994 & 5 & 12 & 7 & $(1)$ \\
1995 & 10 & 16 & 6 & $(4)$ \\
1996 & 9 & 14 & 5 & $(4)$ \\
Totals & 34 & 55 & 21 & $(14)$ \\
\hline
\end{tabular}

programmes by consultants is so constrained. Only an appreciable increase in senior posts can correct this unsatisfactory situation. We hope that the new demands from the internal market will help to stimulate the growth that is so urgently needed.

We are especially concerned that the number of Health Districts without adequate expertise in cardiology did not fall during the year since the previous survey. Where provision is particularly poor or even absent the pressure for improvement is restrained because the public, general practitioners, and even hospital consultants have little awareness of what can be provided.

Even if the new consultant posts that are needed are not created we face a crisis within the next three years because of a shortfall in senior registrar posts. The considerable expansion in cardiology that did take place 25 years ago was reflected in a stepwise near doubling of consultant opportunities from 1997 onwards. We have long been aware of this, but recently the situation has changed because of the move to earlier retirement so that now the increased requirement is somewhat less abrupt but starts from 1995-two years earlier.

The factors that we have to take into account in deciding the number of senior registrar posts that we require are complex. First we have to cater for an expected growth of 5\% per annum (a figure that we have almost reached). Secondly, we have to prepare for the increased opportunities from retirements that will start shortly and continue indefinitely. Thirdly, we have to correct the current tendency for premature appointment to consultant posts-often occurring before three years at senior registrar level, and at the same time take note of the relatively large percentage of posts that are being filled by trainees who are not in approved cardiological posts. On the other hand a reduction in the length of senior registrar training from four years to three will provide some relief, at least theoretically (we recognise, however, that three years is already the average time in post). It is conceivable that part of our immediate shortfall may be met by hospital or departmental

Table 13 Contract expiry dates for senior registrars compared with retirement dates for consultants in Scotland (31 July 1991)

\begin{tabular}{llll}
\hline Year & $\begin{array}{l}\text { Consultants } \\
\text { retiring }\end{array}$ & $\begin{array}{l}\text { Approved } S R s \\
\text { available }\end{array}$ & Balance \\
\hline 1992 & 1 & 2 & 1 \\
1993 & 1 & 1 & 1 \\
1994 & 1 & 1 & \\
1995 & 1 & 2 & 2 \\
1996 & 3 & 7 & 4 \\
Totals & 1 & &
\end{tabular}


Table 14 Contract expiry dates for senior registrars compared with retirement dates for consultants in Northern Ireland ( 31 July 1991)

\begin{tabular}{lllr}
\hline Year & $\begin{array}{l}\text { Consultants } \\
\text { retiring }\end{array}$ & $\begin{array}{l}\text { Approved SRs } \\
\text { available }\end{array}$ & Balance \\
\hline 1992 & 1 & 1 & \\
1993 & & 1 & 1 \\
1994 & 1 & 1 & -1 \\
1995 & & 3 & 1 \\
1996 & 2 & & 1 \\
\hline
\end{tabular}

closures that some see as inevitable. We hope that redeployment (if it occurs) will be only a short-term phenomenon.

We are certain that we need an increase in senior registrar posts, but the complexities make accurate prediction of our requirement very difficult. We recommend as a first step the ending of the top-slicing of 10 posts for research. If a senior registrar or lecturer does go into research there can indeed be an increase in the trainee numbers at any one time, but averaged over the years the numbers entering the senior registrar/lecturer grade and the numbers leaving it are unaffected. The top-slice was therefore always illogical, and has served us poorly because few of the posts are taken up by trainees wishing to enter the specialty. We believe that these 10 posts should be distributed as soon as possible between approved NHS posts and lecturer posts, leaving our overall number of senior registrar/lecturer positions at the present level of 60. (Our data at present suggest that we do have an excess of two so the real "gain" may appropriately be eight posts.) Unfortunately the interval be- tween JPAC approval and having an individual appointed is about two years, so it is inevitable that posts will continue to be filled by trainees from non-approved positions and from those in other specialties such as clinical pharmacology. We also believe that at this time of rapid change in service provision and in the pattern of training we need an annual review; without this we have little chance of matching trainees to future consultant opportunity with a balance that is in any way acceptable.

Future surveys and annual reports must also take note of registrar numbers, but calculations for this grade clearly depend upon sound planning at senior registrar and consultant levels.

1 Chamberlain DA, Goodwin JF, Emanuel RW, Bailey LG. Career prospects in cardiology in England and Wales. Survey of 15 health regions. Br Heart $J 1981 ; 45: 460-3$.

2 Chamberlain D, Bailey L, Emanuel R, Oliver M. Staffing and facilities in cardiology in England and Wales July 1982. Second biennial survey. Br Heart J 1985;50: 597-604.

3 Chamberlain D, Bailey L, Julian D. Staffing and facilities in cardiology in the United Kingdom 1984. Third biennial survey. $B r$ Heart $J 1986 ; 55: 311-20$.

4 Chamberlain D, Bailey L, Sowton E, Ballantyne D, Boyle D McC, Oliver M. Staffing in cardiology in the United $\mathrm{McC}$, Oliver $\mathrm{M}$. Staffing in cardiology in the United
Kingdom 1988. Fifth biennial survey. Br Heart $J$ 1989;62:482-7.

5 Chamberlain D, Pentecost B, Reval K, Stevens J, Boyle D McC, Cobbe S, Ballantyne D, Shaw T. Staffing in cardiology in the United Kingdom 1990. Sixth biennial survey: with data on facilities in cardiology in England and Wales 1989. Br Heart $J$ 1991;66:395-404.

6 Fourth Report of a Joint Cardiology Committee of the Royal College of Physicians of London and the Royal College of Surgeons of England. Provision of services for the diagnosis and treatment of heart disease. Br Heart J 1992;67: 106-16. 